\title{
Determination of Quinine Clearance in Chronic Renal Failure During Haemodialysis
}

\author{
Christophe N'cho Amin ${ }^{1}$, Philippe André Sawa Kpaibé ${ }^{1}$, Nicaise François Bony ${ }^{1}$, \\ Gildas Komenan Gbassi ${ }^{1}$, Michèle Aké ${ }^{1}$, Apollinaire Gnionsahé ${ }^{2}$, Eugène Atindehou ${ }^{1}$ \\ ${ }^{1}$ Department of Analytical Chemistry, General Chemistry and Inorganic Chemistry, Faculty of Pharmaceutical and Biological Sciences, \\ University of Félix Houphouët-Boigny, Abidjan, Côte d'Ivoire \\ ${ }^{2}$ Hemodialysis Centre, University Hospital of Cocody, Abidjan, Côte d'Ivoire
}

Email address:

amin.ncho@yahoo.fr (C. N'cho Amin), andresawa@yahoo.fr (P. A. S. Kpaibé), gildas_gbassi@yahoo.fr (G. K. Gbassi), bonynicaise@yahoo.fr (N. F. Bony),dominique_ake@yahoo.fr (M. Aké), gnions-daze@hotmail.com (A. Gnionsahe), atingene@yahoo.fr (E. Atindehou)

\section{To cite this article:}

Christophe N'cho Amin, Philippe André Sawa Kpaibé, Nicaise François Bony, Gildas Komenan Gbassi, Michèle Aké, Apollinaire Gnionsahé, Eugène Atindehou. Determination of Quinine Clearance in Chronic Renal Failure During Haemodialysis. Science Journal of Analytical Chemistry. Vol. 4, No. 3, 2016, pp. 26-29. doi: 10.11648/j.sjac.20160403.12

Received: April 6, 2016; Accepted: April 18, 2016; Published: May 3, 2016

\begin{abstract}
Hemodialysis is a method that used to achieve the extracorporeal removal of waste products such as creatinine and urea and free water from the blood when the kidneys are in a state of renal failure. However, this treatment may reduce the effectiveness of certain drugs. It is necessary to study the dialysance of quinine, a drug used in first intention for the treatment of severe malaria due to the fragility of uremic patients and the presence of malaria in endemic areas. This study has been conducted at the hemodialysis center of SAMU (Service d'Aide Médicale d'Urgence) in Abidjan Cocody. Twenty one (21) subjects with chronic renal failure aged of 24 to 50 years were enrolled. Two groups of subjects were formed. Each patient of the first group $(9$ subjects) received per person one tablet of $500 \mathrm{mg}$ of quinine base (single dose) before the hemodialysis started. The second group (12 subjects) received in perfusion $5 \%$ glucose solution $(250 \mathrm{~mL})$ containing $10 \mathrm{mg} \cdot \mathrm{kg}^{-1}$ of quinine base during 4 hours. The perfusion system and the hemodialysis system were conducted simultaneously. The concentrations of quinine in the tablet, the perfusion solution and the human blood were determined by a validated high performance liquid chromatography method. Quinine content in tablet and perfusion solution was in agreement with the manufacturer's specifications. The clearance of quinine was $23.67 \mathrm{~mL} \cdot \mathrm{min}^{-1}$. It appeared of this study that quinine fraction extracted did not require dose adjustment.
\end{abstract}

Keywords: HPLC, Antimalarial, Quinine, Hemodialysis, Chronic Renal Failure

\section{Introduction}

Chronic renal failure is a fairly common cause of hospitalization in internal medicine where his prognosis is terrible [1]. The common treatment is the dialysis. Hemodialysis is a method that used to achieve the extracorporeal removal of waste products such as creatinine, urea and free water from the blood when the kidneys are in a state of renal failure [2]. However, this treatment may reduce the effectiveness of certain drugs used to treat other illness as malaria in patients with chronic renal failure. Malaria remains the first cause of hospital consultation in Côte d'Ivoire. All the population is affected but particularly children from the first few months of life to the age of 5 years, pregnant women and subjects suffering from certain chronic diseases as chronic renal failure. The strategy adopted by the Ivorian national program against malaria to reduce morbidity and mortality due to severe falciparum malaria is based on quinine treatment at $25 \mathrm{mg} / \mathrm{kg} / 24 \mathrm{~h}$ at three times the first day and twice-daily the other days (2-5 days) [3, 4]. Due to the fragility of uremic patients and the presence of malaria in endemic areas such as Côte d'Ivoire, it is necessary to study the dialysance of quinine, a drug used in first intention for the treatment of severe malaria. The aim of this study was to know whether hemodialysis affects the efficacy of quinine. Thus, quinine concentration determined by HPLC method $[5,6,7]$ has been 
studied in subjects with chronic renal insufficiency during the dialysis session.

\section{Material and Methods}

The patients of the study are from the hemodialysis center of SAMU (Service d'Aide Médicale d'Urgence) in Abidjan Cocody. Analyses were conducted in the department of chemistry (Faculty of Pharmacy, University Félix Houphouët-Boigny). The protocol was approved by the hospital local ethics committee. Patients with chronic renal failure treated by regular haemodialysis participated in the protocol after providing informed consent.

\subsection{Chemicals}

All chemicals and solvents were of analytical grade from different suppliers. Quinine was from Sigma Aldrich (Saint Quentin Fallavier, France). Methanol, hydrochloric acid were from Sigma-Aldrich (Steinheim, Germany), acetonitrile HPLC grade from Panreac (Istanbul, Turkey), ammonium acetate GPR Rectapur from Prolabo (Paris, France), tetrahydrofuran Normapur from VWR Chemicals (Leicestershire, England). Quinimax ${ }^{\circledR}$ (Sanofi wintrop), commercial tablet and injectable formulations, were purchased from a pharmacy in Côte d'Ivoire.

\subsection{Patients and Quinine Administration}

Patients with chronic renal failure enrolled were 24 to 50 years old, sex male, hemoglobin upper to $8 \mathrm{~g} \cdot \mathrm{dL}^{-1}$ and serum protein upper than 65 g. $\mathrm{L}^{-1}$. Twenty one $(21)$ subjects with chronic renal failure were enrolled. Two groups (1 and 2) of subjects were formed. Nine (9) subjects for group 1 received per os one tablet of $500 \mathrm{mg}$ of quinine (single dose) before the hemodialysis started. The second group (12 patients) received in perfusion $5 \%$ glucose solution $(250 \mathrm{~mL})$ containing 10 mg. $\mathrm{kg}^{-1}$ of quinine base during 4 hours while the dialysis time was 5 hours. The perfusion system and the hemodialysis system were conducted simultaneously.

\subsection{Blood Samples}

Heparinized blood samples for determination of serum concentrations of quinine, urea and creatinine were obtained from artery and venous lines at 0, 30, 60, 120, 240 and 300 min when the patient is connected to hemodialysis system. Samples were centrifuged and plasma was stored at $-70^{\circ} \mathrm{C}$ until analyzed.

\subsection{Determination of Quinine}

The concentrations of quinine in Quinimax ${ }^{\circledR}$ tablet, Quinimax ${ }^{\circledR}$ injectable solution for perfusion and in the human blood serum were determined by a high performance liquid chromatography (Shimadzu) method.

Standard solution and test solution

A standard solution containing $4.8 \mu \mathrm{g} \cdot \mathrm{mL}^{-1}$ of quinine is prepared in a volumetric flask by agitation of an accurately weighed amount of quinine in methanol/hydrochloric acid
0.1 equiv. $L^{-1}(\mathrm{v} / \mathrm{v})$

Test solutions for tablet formulation corresponding to theoretical quinine concentration $\left(4.8 \mu \mathrm{g} \cdot \mathrm{mL}^{-1}\right)$ are prepared from an accurate amount of powdered tablet following the same procedure. After centrifugation of the extract at 5000 rpm for $5 \mathrm{~min}$, the supernatant was injected in the chromatographic system.

Test solutions for injectable formulation corresponding to theoretical quinine concentration $\left(4.8 \mu \mathrm{g} \cdot \mathrm{mL}^{-1}\right)$ are prepared by dilution in the same working solution.

For blood serum sample treatment, a liquid/liquid extraction was applied to a whole blood sample using acetonitrile for the deproteinization. Centrifugation was set at $5,000 \mathrm{rpm}$ for $15 \mathrm{~min}$.

Apparatus and operating conditions

A Shimadzu HPLC equipment was used. A Supercosil column LC 25-cm x 4.6-mm, RP18 reverse-phase column was eluted with an acetonitrile/ammonium acetate buffer/ tetrahydrofuran: 15:60:25 (v/v/v), $\mathrm{pH} 3$; at a flow rate of 1.0 $\mathrm{mL} \cdot \mathrm{min}^{-1}$. A fluorescence detector was set at $350 \mathrm{~nm}$ for excitation wavelength and $425 \mathrm{~nm}$ for emission wavelength.

\subsection{Other Biochemical Assays}

Urea and creatinine were determined respectively by an enzymatic (urease) method and by the Jaffe reaction.

\subsection{Calculate of the Clearance}

Substance clearance was determined by the formula $\mathrm{Cl}=\mathrm{QB}$ $\left(\mathrm{C}_{\text {Artery }}-\mathrm{C}_{\text {Vein }}\right) / \mathrm{C}_{\text {Artery }}$, where $\mathrm{Cl}=$ clearance; $\mathrm{QB}=$ hemodialysis flow rate, $\mathrm{C}_{\text {Artery }}$ substance concentration in arterial blood and $\mathrm{C}_{\text {Vein }}$ substance concentration in venous blood.

\section{Results and Discussion}

\subsection{Preliminary Studies}

The method used in this study derived from Sharma et al.'s method [7] due to its simplicity. Their mobile phase was consisted of acetonitrile/sodium acetate buffer $5 \mathrm{mmol} . \mathrm{L}^{-1}$ $(23: 77, \mathrm{v} / \mathrm{v}), \mathrm{pH} 3$. Sodium acetate buffer was replaced with ammonium acetate buffer because alkaloids are better separated in the presence of ammonium salt [8]. Quinine asymmetry peak obtained was corrected by adding tetrahydrofuran, an organic modifier [9]. The final mobile phase consisted of acetonitrile/ammonium acetate buffer/ tetrahydrofuran (15:60:25, v/v/v), $\mathrm{pH} 3$.

\subsection{Validation Method of Quinine Determination}

Linearity of the calibration line over the range 0.02-20 $\mu \mathrm{g} \cdot \mathrm{mL}^{-1} \quad\left(\mathrm{r}^{2}=0.999\right)$, recovery (in the range 94-102\%), repeatability $(\mathrm{RSD}<5 \%, \mathrm{n}=6)$ and $\operatorname{LOD}\left(2 \cdot 10^{-7} \mu \mathrm{g} \cdot \mathrm{mL}^{-1}\right)$ are summarized in the Table 1.

\subsection{Determination of Quinine in Quinimax ${ }^{\circledR}$ Commercial Formulations}

Quinine drug is frequently used to treat severe malaria in 
endemic regions. To prevent fake medicine, commercial quinine was analyzed before using by patients with chronic renal failure in the present study. Quinine content in tablet and injectable solution was in agreement with the manufacturer's specifications (Table 2).

Table 1. Validation method of quinine determination in commercial formulation and in blood sample.

\begin{tabular}{lll}
\hline & $\begin{array}{l}\text { Pharmaceutical } \\
\text { formulation }\end{array}$ & $\begin{array}{l}\text { Blood serum } \\
\text { sample }\end{array}$ \\
\hline $\begin{array}{l}\text { Linearity } \\
\text { Repetability }(\mathrm{n}=6) \text { of various standard } \\
\text { solutions }(0.35,1,2.4,4.8 \text { and } 10\end{array}$ & $\mathrm{y}=1451.7 \mathrm{x}+78.0, \mathrm{r}^{2}=0.9999$ \\
$\left.\mu \mathrm{g} \cdot \mathrm{mL}^{-1}\right)$ & $1.36-1.71 \%$ & \\
$\begin{array}{l}\text { Repeatability of an extract }(\mathrm{n}=6) \\
\begin{array}{l}\text { Repeatability of the analytical } \\
\text { procedure (n=6) }\end{array}\end{array}$ & $1.3 \%$ & $3.8 \%$ \\
$\begin{array}{l}\text { Recovery } \\
\text { Limit of quantification }\left(\mathrm{LOQ}, \mu \mathrm{g} \cdot \mathrm{mL}^{-1}\right)\end{array}$ & $2.10^{-6}$ & $4.9 \%$ \\
\begin{tabular}{l} 
Limit of detection $\left(\mathrm{LOD}, \mu \mathrm{g} \cdot \mathrm{mL}^{-1}\right)$ \\
\hline
\end{tabular} & $2.10^{-7}$ & $97.1 \%$ \\
\hline
\end{tabular}

Table 2. HPLC determinations of quinine in commercial formulations.

\begin{tabular}{lll}
\hline Form & Commercial formulation & Quinine (mg) \\
\hline $\begin{array}{l}\text { Injectable } \\
\text { solution }\end{array}$ & Quinimax $125^{\circledR}$ containing $120 \mathrm{mg}$ of quinine & $120.99 \pm 4.03$ \\
& Quinimax $250^{\circledR}$ containing $240 \mathrm{mg}$ of quinine & $239.39 \pm 4.53$ \\
& Q uinimax $500^{\circledR}$ containing $480 \mathrm{mg}$ of quinine & $490.62 \pm 8.03$ \\
Tablet & Quinimax $500^{\circledR}$ containing $480 \mathrm{mg}$ of quinine & $494.55 \pm 9.37$ \\
\hline
\end{tabular}

\subsection{Determination of Quinine, Urea and Creatinine During Dialysis}

Quinine concentrations determined in artery blood and in venous blood after oral and intravenous administration of quinine were presented in figure 1. The concentrations of quinine in the artery blood and venous blood are not different after oral administration of quinine in all blood sampling. It is the same after intravenous administration of quinine at the end of quinine perfusion. Concentrations of urea and creatinine were shown in figure 2. These substances decrease during hemodialysis. Differences of ureamia and creatininemia are respectively significant between artery blood and venous blood.

\subsection{Calcul of Clearance}

Quinine clearance after oral administration in the group 1 was $26.94 \pm 11.63 \mathrm{~mL} \cdot \mathrm{min}^{-1}$. The clearance after IV administration in the group 2 was $21.22 \pm 13.97 \mathrm{~mL} \cdot \mathrm{min}^{-1}$. The comparison of these quinine clearance is not significant $\left(\mathrm{t}=0.242<\mathrm{t}_{0.05}(2.080)\right)$. There were no significant changes in plasma quinine concentrations in patients with chronic renal failure during hemodialysis. Similar results were obtained in acute renal failure [10]. Non dialyzable quinine is also shown in two patients with severe malaria and renal failure requiring dialysis [7]. The clearance of quinine was evaluated to 23.67 $\mathrm{mL} \cdot \mathrm{min}^{-1}$. There is a low quinine fraction extracted compared to urea and creatinine. It represented respectively $14.97 \%$ and $18.70 \%$ of the clearance of urea $(159.73 \pm 24.29) \mathrm{mL}_{\mathrm{min}}{ }^{-1}$ and creatinine $(124.96 \pm 22.44) \mathrm{mL} \cdot \mathrm{min}^{-1}$.

\section{Conclusion}

Quinine content in tablet and injectable solution used for studying the clearance of quinine in hemodialysis was in agreement with the manufacturer's specifications. Similar quinine clearances in hemodialysis were noted after oral and IV administration. Quinine clearance during hemodialysis was $23.67 \mathrm{~mL} \cdot \mathrm{min}^{-1}$. The low quinine fraction extracted by an artificial kidney does not require a dose adjustment of this antimalarial treatment during hemodialysis.

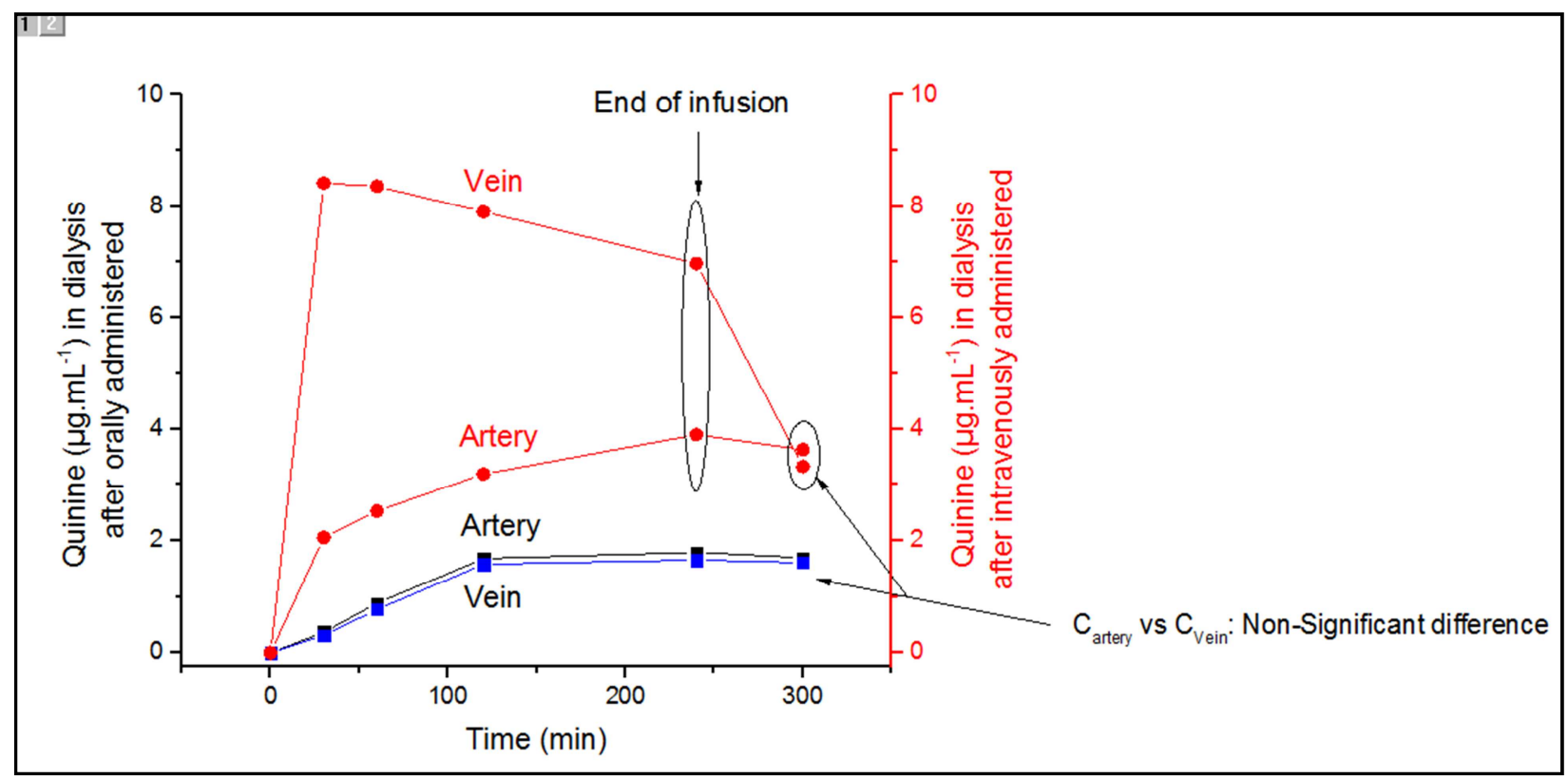

Figure 1. Concentration (C) of quinine during dialysis. 


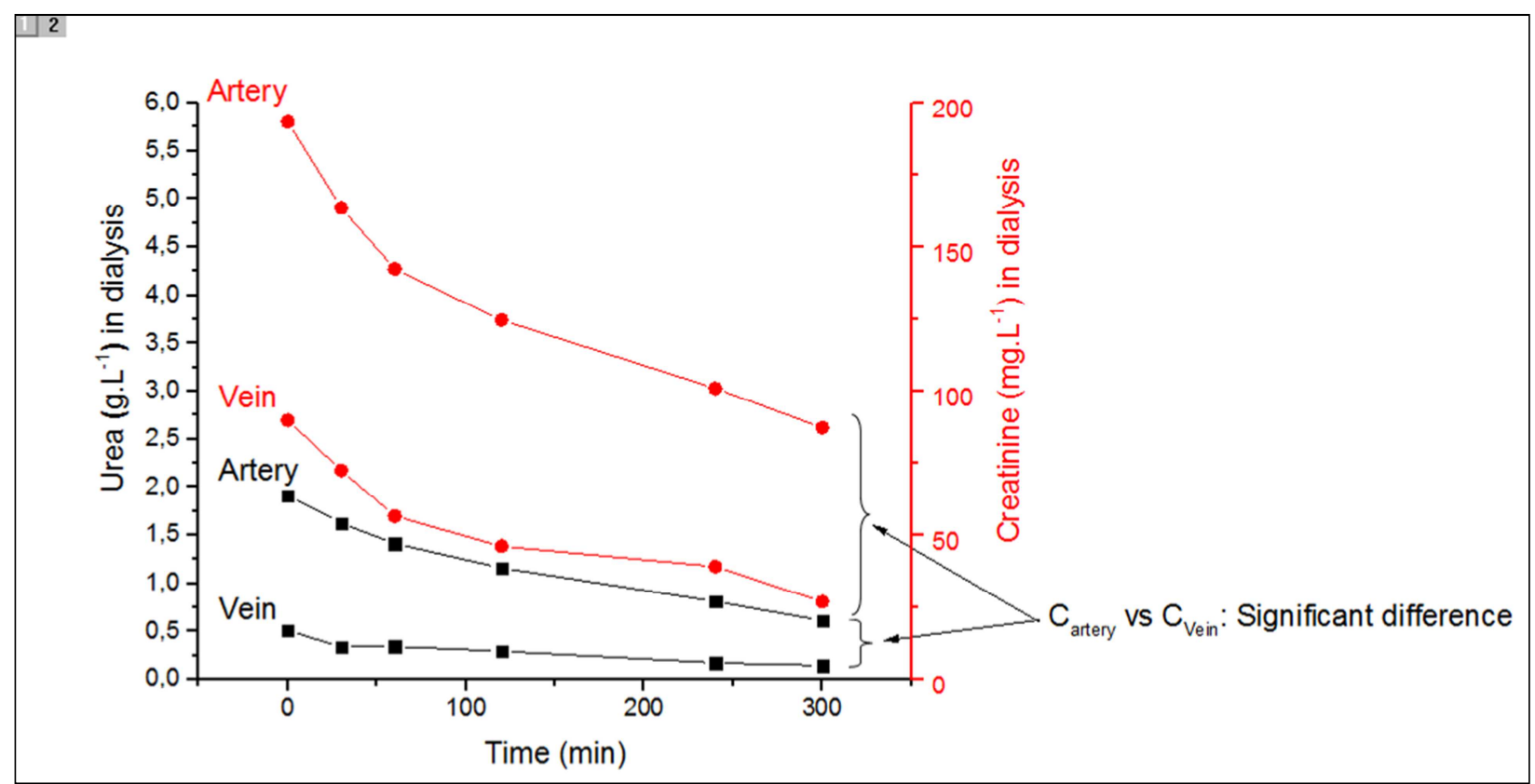

Figure 2. Concentration (C) of urea and creatinine during dialysis.

\section{Acknowledgment}

The laboratory is grateful to Patrick Balley for his technical contribution.

\section{References}

[1] B. Ouattara, O. Kra, H. Yao, K. Kadjo, E. K. Niamkey, Particularités de l'insuffisance rénale chronique chez des patients adultes noirs hospitalisés dans le service de médecine interne du CHU de Treichville, Néphrol. \& Thér. 7 (2011) 531-534.

[2] D. A. Gnionsahé, W. M. Tia, P. N. A. Coulibaly, D. A. Lagou, C. Ackoundou-N'guessan, M. A. Moudachirou, Circonstances de démarrage de la dialyse en Afrique : expérience d'un hôpital public en Côte d'Ivoire, Rev. Int. Sc. Méd. 16 (2014) 44-46.

[3] World Health Organization, Severe falciparum malaria, Trans. R. Soc.Trop. Med. Hyg. 94 (2000) supplement 1.

[4] Ministère chargé de la santé en Côte d'Ivoire, Programme National de lutte contre le Paludisme (2004) 1-33.
[5] L. Roy, M. Leblanc, P. Bannon, J-P. Villeneuve, Quinine pharmacokinetics in chronic hemodialysis patients, Br. J. Clin. Pharmacol. 52 (2002) 604-609.

[6] V. F. Samanidou, E. N. Evaggelopoulou, I. N. Papadoyannis, Simultaneous determination of quinine and chloroquine anti-malarial agents in pharmaceuticals and biological fluids by HPLC and fluorescence detection, J. Pharm. Biomed. Anal. 38 (2005) 21-28.

[7] A. M. Sharma, F. Keller, M. Boeckh, J. Heitz, K. Borner, Quinine dosage in severe malaria with renal failure necessitating hemodialysis, Eur. J. Clin. Pharmacol. 36 (1989) $535-536$.

[8] D. V. McCalley, Analysis of the Cinchona al-kaloids by high-performance liquid chromatography and other separation techniques, J. Chromatogr. A 967 (2002) 1-19.

[9] S. Ahuja, Chromatography and separation science, Amsterdam; Boston: Academic Press, 2003.

[10] K. Sukontason, J. Karbwang, W. Rimchala, T. Tin, K. Na-Bangchang, V. Banmairuroi, D. Bunnag, Plasma quinine concentrations in falciparum malaria with acute renal failure, Trop. Med. Int. Health 1 (1996) 236-242. 